\title{
Prognosticating for Adult Patients With Advanced Incurable Cancer: a Needed Oncologist Skill
}

Christina Chu, BMedSci, MBChB, MRCP

Rebecca Anderson, MSc

Nicola White, $P h D$

Patrick Stone, MA, MD, FRCP

\author{
Address \\ *Marie Curie Palliative Care Research Department, Division of Psychiatry, Univer- \\ sity College London (UCL), 6th Floor, Maple House, 149 Tottenham Court Road, \\ London, W1T 7NF, UK \\ Email: p.stone@ucl.ac.uk
}

Published online: 16 January 2020

(C) The Author(s) 2020

Keywords Prognosis · Prediction · Palliative care · Neoplasms · Communication · Uncertainty

\section{Opinion statement}

Patients with advanced cancer and their families commonly seek information about prognosis to aid decision-making in medical (e.g. surrounding treatment), psychological (e.g. saying goodbye), and social (e.g. getting affairs in order) domains. Oncologists therefore have a responsibility to identify and address these requests by formulating and sensitively communicating information about prognosis. Current evidence suggests that clinician predictions are correlated with actual survival but tend to be overestimations. In an attempt to cultivate prognostic skills, it is recommended that clinicians practice formulating and recording subjective estimates of prognosis in advanced cancer patient's medical notes. When possible, a multi-professional prognostic estimate should be sought as these may be more accurate than individual predictions alone. Clinicians may consider auditing the accuracy of their predictions periodically and using feedback from this process to improve their prognostic skills.

Clinicians may also consider using validated prognostic tools to complement their clinical judgements. However, there is currently only limited evidence about the comparative accuracy of different prognostic tools or the extent to which these measures are superior to clinical judgement. Oncologists and palliative care physicians should ensure that they receive adequate training in advanced communication skills, which builds upon their pre-existing skills, to sensitively deliver information on prognosis. In particular, clinicians should acknowledge their own prognostic 
uncertainty and should emphasise the supportive care that can continue to be provided after stopping cancer-directed therapies.

\section{Introduction}

Prognostication is the process of making predictions about future health outcomes, usually about predicting length of survival. Patients with advanced cancer frequently express a desire for prognostic information [1]. However, simply being told that one is "terminal" or "incurable" does not usually provide sufficient information for patients or families to make detailed plans for the future [1,2]. Even if patients do not wish to know exact timescales, they may want to have prognostic information to inform treatment discussions, undertake advance care planning, or help with decision-making [3, 4]. Clinicians commonly find it difficult to make these predictions and to discuss them with patients and relatives, leading to unmet information needs $[5,6]$. Communication in this area is complex and requires skill and experience, particularly in finding the balance between conveying useful information about expected timeframes, while also explaining the inherent uncertainty in such predictions. Advanced communication skills should therefore be considered an essential element in the process of prognostication [7].

The prognosis of an individual patient is liable to change over time and to be influenced by biological, clinical, and social factors beyond diagnosis and stage of disease $[8,9]$. Therefore, it is important for oncologists to develop and maintain skills in predicting survival even when the disease has become incurable and disease-directed treatment options are limited or nonexistent. This is distinct from the more common practice of staging cancers to derive median survival estimates at diagnosis or the use of prognostic markers to predict response to treatment.

A prognostic estimate can be formulated using a clinician's experience and knowledge to make a judgement; this is known as a clinical prediction of survival. Although widely used, there are concerns about the subjective nature of this approach, which makes it difficult to reproduce and teach. Also, subjective judgements tend to be inaccurate and over-optimistic $\left[10,11^{\bullet}, 12\right]$. Therefore, more "objective" scales and tools have been developed to support clinical predictions $\left[13,14^{\bullet \bullet}\right]$.

The aim of this paper is to evaluate the recent literature on prognostication for patients with advanced cancer and to suggest ways in which physicians can improve their own clinical practice in formulating and communicating prognostic estimates.

\section{Clinical prognostic estimates}

Clinical prognostic estimates usually take one of two formats: temporal (how long?) or probabilistic (how likely?). Temporal predictions can either be specific (e.g. "two days") or can use broader categories (e.g. "one to two months"). Probabilistic predictions estimate the likelihood of patients surviving to specific time points (e.g. "70\% chance of surviving two weeks"). An alternative option is for clinicians to ask themselves the Surprise Question (SQ); "would I be surprised if this patient were to die in the next 6-12 months?" [15]. The SQ was developed to prompt clinicians to consider whether patients would benefit from a shift in focus of care or from referral to specialist palliative care services, rather than as a method of prognostication per se. The original SQ has been modified to use different time frames (e.g. 30 days) [16, 17], or to consider survival rather than death; "would I be surprised if this patient were to be alive in the next 6-12 months?" $[18,19]$. The SQ is a prompt for introspection, 


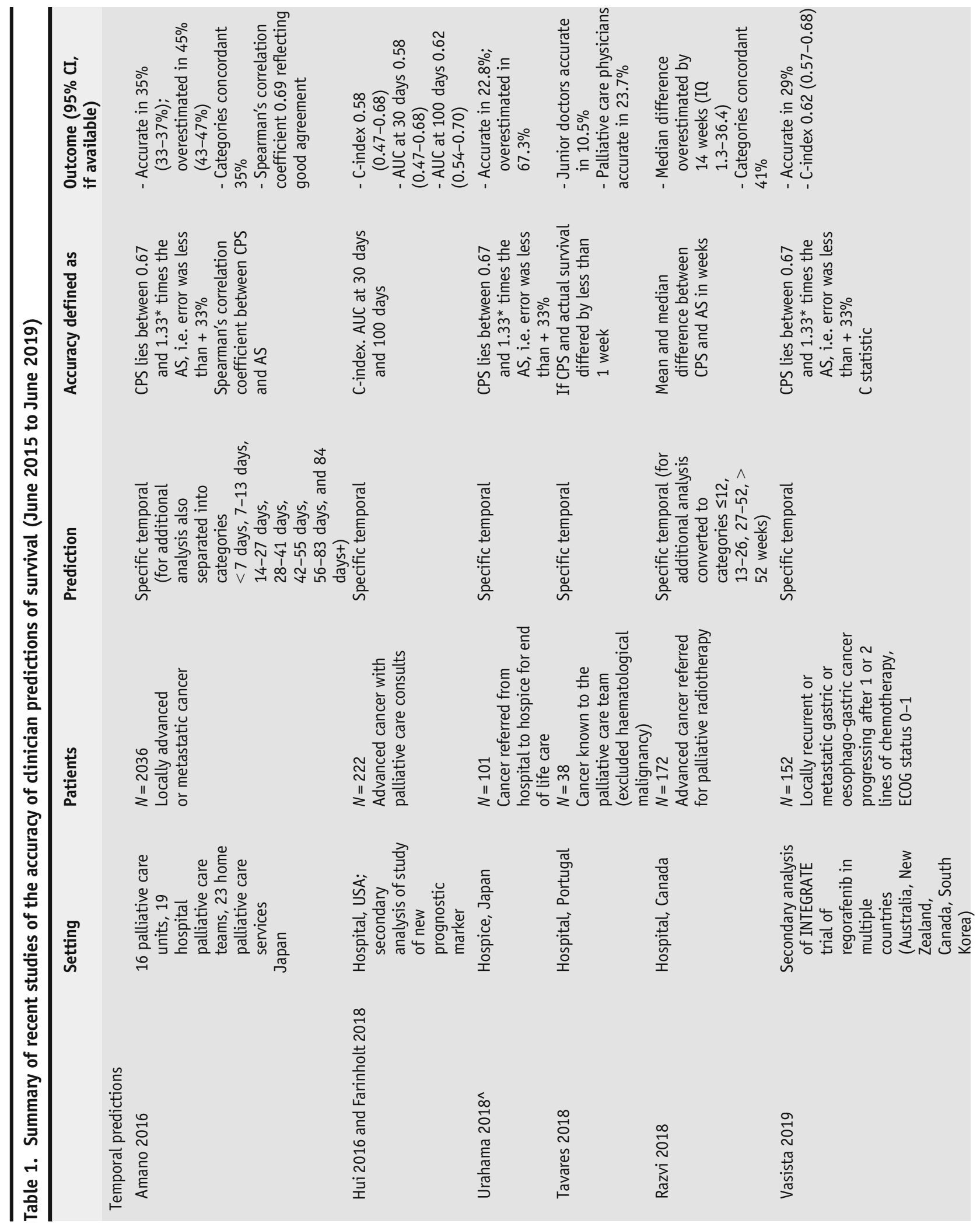



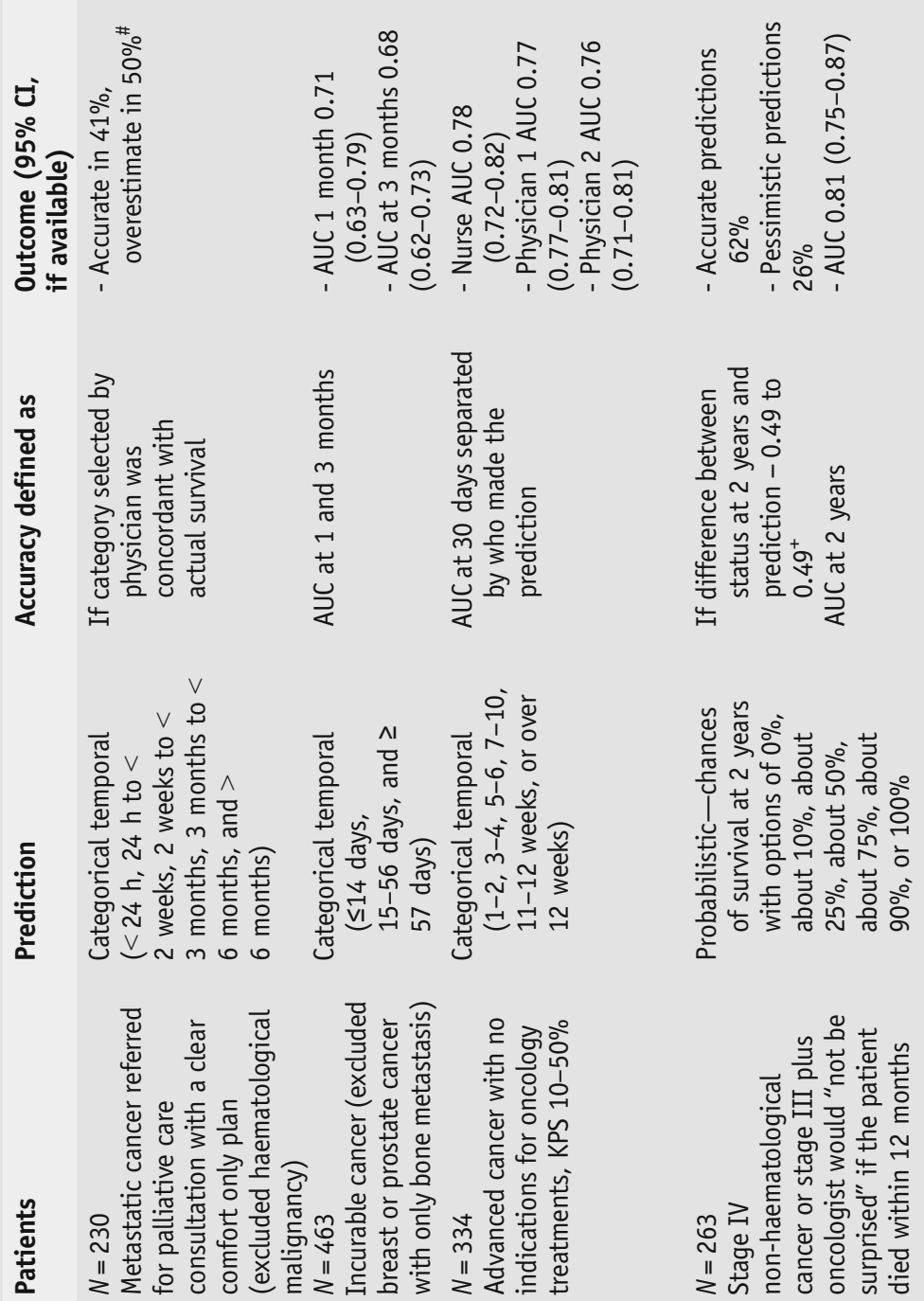

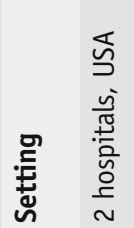
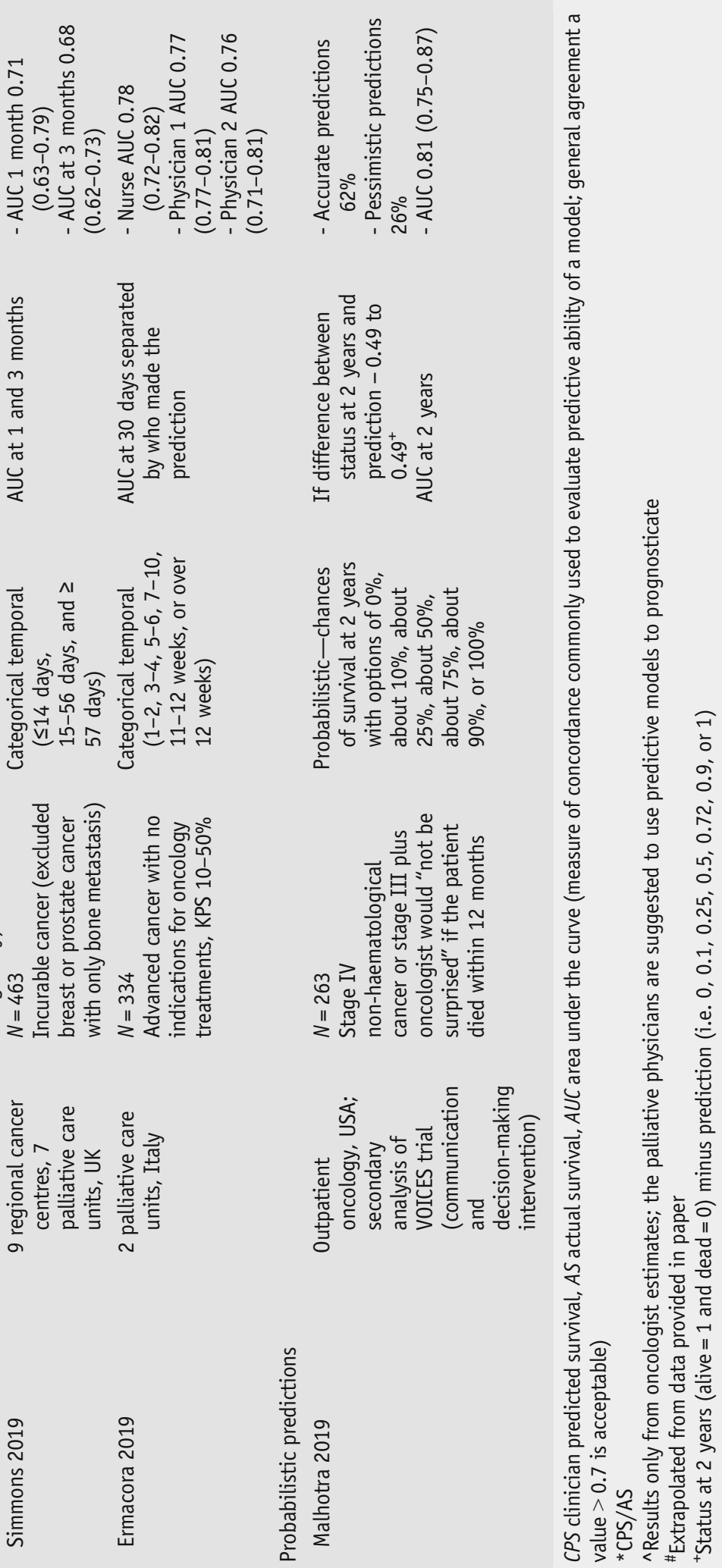
encouraging clinicians to consider the possibility that the patient may die in the foreseeable future rather than asking them to make a specific prediction about how long they will live.

How accurate are clinical predictions of survival?

\section{Temporal and probabilistic predictions}

There is a growing body of evidence about the accuracy of clinician predictions of survival. In preparation for this review, the authors identified two relevant systematic reviews $\left[10,11^{\bullet \bullet}\right]$ and ten further articles published in the last 4 years (summarised in Table 1) [20-29].

Clinician predictions are correlated with actual survival, but there is a wide variation in reported accuracy, with a general tendency to overestimate [10, $\left.11^{\bullet \bullet}, 12,20-23\right]$. Clinicians' specific predictions range from underestimating by half to a sixfold overestimation $\left[10,11^{\bullet \bullet}\right.$. One large prospective cohort study of 2036 locally advanced or metastatic cancer patients accessing palliative care services found that $45 \%$ predictions were overestimates, 35\% accurate, and $20 \%$ underestimates [20].

There is a lack of consensus in the literature about what constitutes an "accurate" prediction, which makes interpretation of study results challenging. For example, should a prediction of 12 weeks be considered "accurate" if the patient dies 2 weeks before or after this? For specific temporal predictions, a common approach is to regard a prognosis as accurate if actual survival falls within $\pm 33 \%$ of the prediction $[20,21,25,30]$. One limitation of this definition is that the magnitude of the absolute permissible error is small when the estimated prognosis is short and is fairly large when the estimated prognosis is longer. Thus, a clinical prediction of survival of 3 days may be judged inaccurate if the patient dies in less than $48 \mathrm{~h}$, whereas a prediction of 3 months may be considered accurate even if the patient dies 4 weeks earlier than expected. The level of "inaccuracy" that is clinically significant remains unclear; at what point does a more "accurate" prognosis alter the management plan or come to be considered important by patients or their relatives?

The issue of defining "accuracy" is magnified for probabilistic estimates. How, for instance, should one judge the accuracy of a prediction that a patient has $40 \%$ chance of surviving 2 weeks? A similar conundrum confronts weather forecasters who often provide probabilistic estimates about, for example, the chances of rain tomorrow. Professional forecasters tend to judge probabilistic predictions using the Brier score [31]. This statistic reflects the degree to which a prediction was correct or incorrect. Thus, a prediction of $90 \%$ is "more correct" than a prediction of $70 \%$ if the event did actually occur. Brier scores range between 0 (accurate) and 1 (inaccurate) with a score of 0.25 representing a prediction of $50 \%$. To our knowledge, only two studies have utilised the Brier score to assess the accuracy of clinicians' survival predictions $\left[32,33^{\circ}\right]$. The mean Brier scores in these studies were 0.22 and 0.24 suggesting clinician's probabilistic predictions are slightly better than chance.

There is mixed evidence about whether certain health professionals are better prognosticators than others or whether prognostic ability improves with experience or seniority $\left[11^{\bullet \bullet}\right]$. However, there is some evidence that multi- 
professional estimates are more accurate than predictions made by individual clinicians alone [34, 35]. In order to develop expertise, repeated "deliberate practice" is required $[36,37]$. Deliberate practice is a structured activity that explicitly aims to improve performance by reflecting on the results of the performance and gaining feedback. Therefore, one might suppose that clinicians ought to be able to improve the accuracy of their prognoses through deliberate practice, although this hypothesis has not yet been tested.

In summary, despite the significant methodological difficulties associated with judging prognostic accuracy, there is fairly consistent evidence that clinicians' estimates correlate with actual survival. It appears that clinicians, regardless of the method of prognostication, do recognise when patients are deteriorating.

\section{Surprise Question}

In systematic reviews, the SQ tends to be more accurate in cancer patients than in patients with other life-threatening conditions $[38,39]$. For patients with cancer, the SQ has a positive predictive value (proportion of patients who die when the clinician would not be surprised by their death) of $46.8-49.3 \%$, a negative predictive value (proportion of patients who survive when the clinician would be surprised by their death) of 92.3-92.4\%, a sensitivity (the proportion of those correctly identified as dying) of $77.1 \%$, and a specificity (proportion of patients correctly identified as surviving) of $84.3 \%$. Referral to palliative care services is seldom based solely on having a poor prognosis; however, early identification of palliative care patients is often triggered by a combination of an expected prognosis of less than a year, combined with complex needs and/or patient choice. Based on the psychometric properties of the SQ, its greatest clinical value may lie in its negative predictive value for "screening out" patients who are unlikely to need immediate referral to specialist palliative care services (all other things being equal). It is, however, important to remember that patients' conditions change and that their prognosis is therefore in need of regular re-appraisal.

\section{Predicting imminent death}

\section{Are clinicians more accurate at predicting imminent death?}

The concept of the "horizon effect" suggests that predictions ought to become more accurate as the event being predicted draws closer [8]. There is conflicting evidence in the literature about whether this is true for survival predictions [20, $22,23,30,40-44]$. In one study, clinicians were asked to provide repeated specific temporal and probabilistic predictions for the following 24 and $48 \mathrm{~h}$, for patients admitted to a palliative care unit [30]. Temporal predictions were defined as accurate if there was an error of less than $\pm 33 \%$. Probabilistic predictions were considered accurate if the clinician predicted $\leq 30 \%$ survival and the patient died, or if the clinician predicted $\geq 70 \%$ survival and the patient survived. Using these definitions, the authors concluded that probabilistic estimates were more accurate than temporal predictions throughout the study period. However, the accuracy of temporal predictions remained constant, whereas the accuracy of probabilistic estimates worsened over the last 14 days 
of life. It is important to note that there have only been a limited number of studies specifically investigating imminent death and the majority have been conducted with patients who have already been identified as suitable for palliative care referral or admission to a palliative care unit. Therefore, these results may not hold true for unselected patient groups on general oncology wards, especially those admitted with acute illnesses.

\section{How do clinicians recognise the last days of life?}

In a Delphi survey of international palliative care experts, there was over 50\% consensus that general deterioration in physical condition, reduced levels of consciousness and cognition, decreased intake of fluid and food, skin changes, altered emotional state, and specific patterns of breathing were features that predicted when patients were entering the last hours and days of life [45]. However, many clinicians also feel they can intuitively recognise when a patient is imminently dying. In semi-structured interviews, staff working in oncology and cardiology wards were asked how they recognised patients who were dying. A range of symptoms, signs, imaging, and laboratory results were reported; however, participants found it very difficult to describe how they assimilated this information, commonly using terms such as having a "subconscious" feeling or a "sixth sense'" that someone was about to die [46].

One way to better understand this so-called sixth sense is to use a research method known as Judgement Analysis [47]. White and colleagues used this approach to investigate which factors subconsciously influenced clinicians' opinions about whether a patient was about to die within the next $72 \mathrm{~h}$

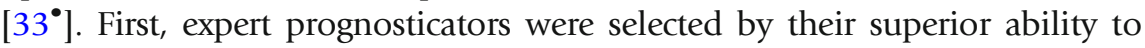
predict imminent death using clinical vignettes based on real patient cases; the expert group had a mean Brier score of 0.184 , reflecting better predictive accuracy, compared to the whole group mean of 0.237 . Next, by altering clinical parameters in fictional cases, the extent to which certain factors affected the experts' judgements could be established. The most influential factor in determining whether clinicians thought that patients were about to imminently die was the Palliative Performance Scale (PPS), followed by the presence or absence of Cheyne-Stokes breathing, general deterioration in the patient's condition, and level of sedation or agitation. Knowing what factors expert prognosticators subconsciously use to formulate their predictions could potentially allow others to learn how to improve their estimates and to better recognise patients who are imminently dying. A randomised controlled trial demonstrates that the use of an online training programme can teach medical students to adopt similar judgement strategies to experts [48]. However, further work will be required to determine how the learning can be consolidated and whether the skills are transferable from the classroom to clinic.

Another method to understand how clinicians might recognise patients who are imminently dying is to identify signs and symptoms that may be pathognomonic of the dying process [49]. In a palliative care context, vital signs (e.g. pulse, blood pressure, and oxygen saturations) have a low sensitivity or positive predictive value for identifying those who are imminently dying, supporting the practice of not routinely undertaking these observations in terminal care settings [50]. However, Hui and colleagues have identified 13 clinical signs which have high specificity $(>95 \%)$ and positive likelihood ratios $(>5)$ of predicting 
the final $72 \mathrm{~h}$ of life $[51,52]$. Sensitivity of these signs rarely reached over $30 \%$, meaning their absence does not exclude imminent death, limiting their use in clinical practice. Nonetheless, this work has informed the development of a clinical tool to aid the diagnosis of impending death [53]. The initial model combines the PPS as a tool to "rule out", and "drooping of nasolabial folds" as a specific sign to help "rule in", impending death. A second model utilises the other 12 signs identified in these studies. Further development and validation is required before this approach can be recommended for clinical use.

\section{Performance scales and prognostic tools}

Performance or functional scales provide a systematic approach to evaluate general well-being and ability to perform activities of daily living. They require clinicians to match signs and symptoms of patients to a description of function on a scale. The Karnofsky Performance Status (KPS) was the first to be developed and consists of single statements describing levels of function from 0 to $100 \%$ [54]; the Australian Modified KPS (AKPS) involves a slight alteration to the phrasing of the statements to provide greater discrimination between certain levels [55]. The PPS is also a modification of the Karnofsky, in which there are five descriptive domains of function rather than a single descriptor [56]. In contrast, the Eastern Cooperative Oncology Group (ECOG) performance scale consists of only five levels [57]. Although not specifically devised as prognostic tools, performance scales have been shown to correlate with survival in a variety of settings [58-60].

In addition to performance scales, there are several tools that have been specifically developed with the aim to predict survival in patients with advanced cancer. A recent systematic review identified seven suitably validated prognostic tools [14*0]: PPS [56], Palliative Prognostic Score (PaP) [61], Delirium Palliative Prognostic Score (D-PaP) [62], Palliative Prognostic Index (PPI) [63], Glasgow Prognostic Score (GPS) [64], B12/CRP index (BCI) [65], and the Prognosis in Palliative Care study predictor models (PiPS-A and PiPS-B) [34]. A summary of these tools is provided in Table 2.

The place of prognostic tools in clinical practice has not yet been clearly defined. Despite validation in relatively large numbers of advanced cancer patients, which has demonstrated adequate discrimination and calibration, there has been limited comparison of their performance against each other or against clinicians' predictions. This means it is often unclear whether these tools perform better, worse, or the same as clinicians making predictions alone. Moreover, it is not always easy to judge how the output of these prognostic tools should be interpreted. The PaP, for instance, predicts whether patients will have a $<30 \%$, a $30-70 \%$, or a $>70 \%$ chance of surviving for the next 30 days. However, it is not clear how one should interpret these results on an individual patient basis. What does a $30-70 \%$ chance of surviving 30 days mean, and how should it be acted upon? Another problem that arises is knowing which tool to use at what time. For example, the PaP and PPI both provide results that may help to distinguish between whether patients will survive for weeks or months, but neither is designed to identify when patients are entering the final days of life. In addition, whether certain tools perform better for patients with certain types of cancers is unknown. These limitations 


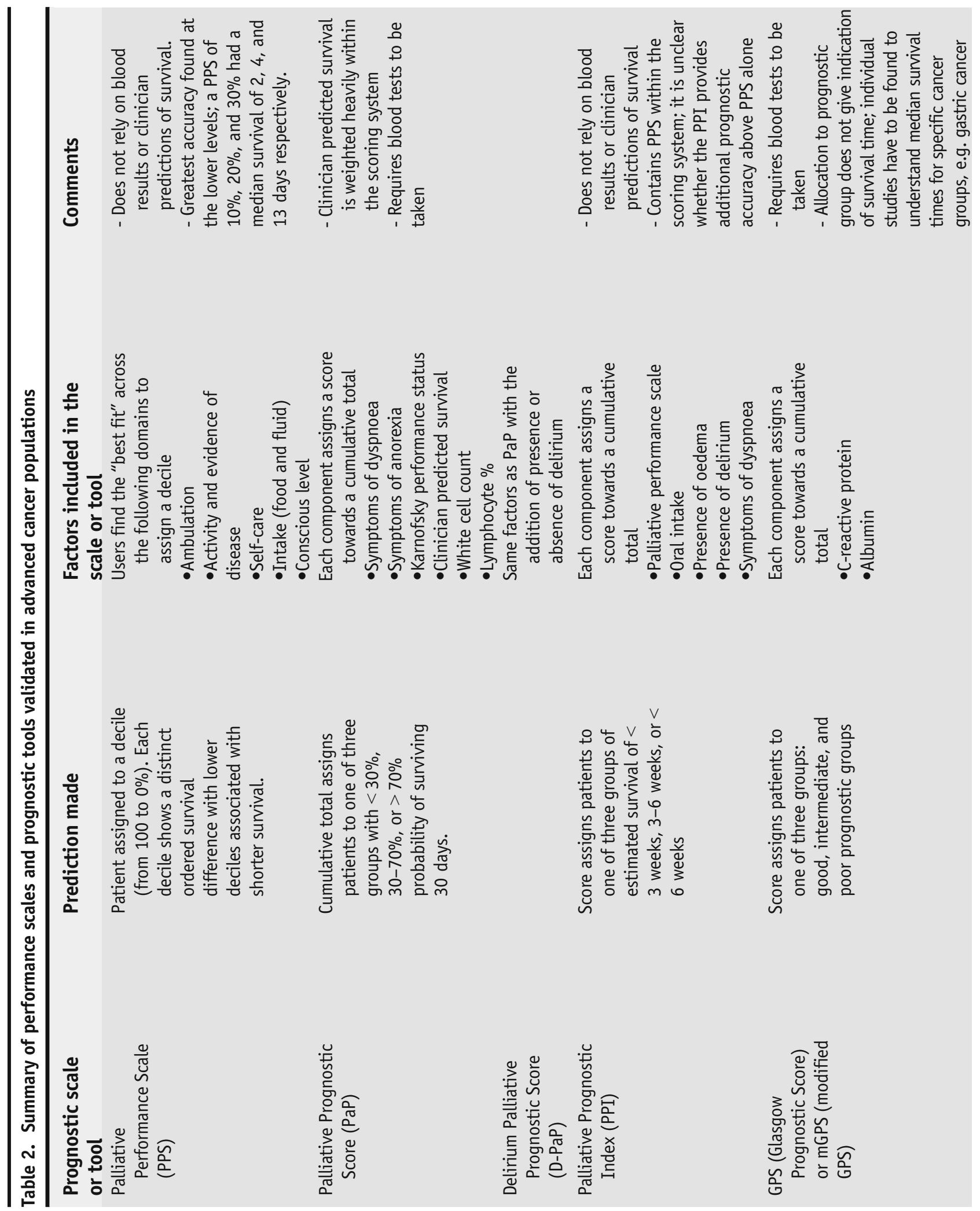




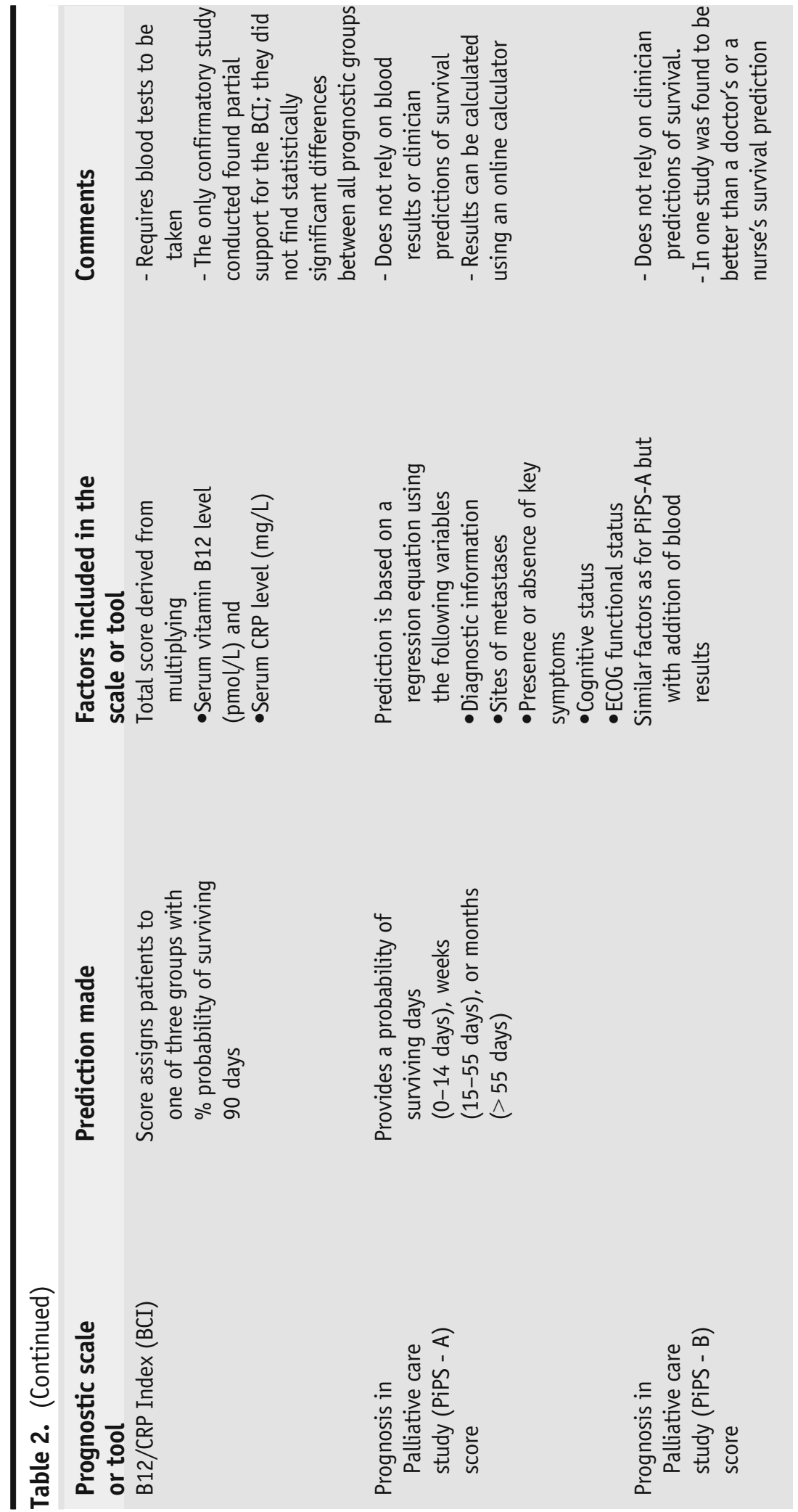


mean that existing prognostic tools cannot yet be recommended as a replacement for clinicians' predictions. For the moment, they should perhaps best be considered as a means of triangulating, or cross-checking, clinicians' own clinical intuitions. They may also have a specific role when clinicians doubt their own judgement or when an "objective" estimate is required, for example for benchmarking of clinical services or determining inclusion and exclusion criteria for clinical trials.

\section{Communicating the prognostic estimate}

\section{Initiating prognostic discussions}

Clinicians often find it difficult to talk about prognosis. Research has shown clinicians sometimes "collude" with patients in creating false optimism, or miss or avoid cues from patients to talk about prognosis, moving straight to talking about treatment options [66, 67]. The desire to focus on the positives is understandable, particularly if it is not clear whether patients are ready to talk about their prognosis. Clinicians therefore need strategies for initiating prognostic conversations sensitively and to pick up on signs from patients that they may be ready to talk about these issues. A recent study recorded hospice outpatient consultations and showed that patients often displayed signs of wanting to discuss prognosis when given the opportunity to influence the consultation $\left[68^{\bullet}, 69\right]$. Patients frequently requested prognostic information by using statements (e.g. "I don't know when it's coming") rather than asking direct questions. These statements allowed doctors to proceed to checking patients' current understanding and their perspectives, and to re-confirm their readiness to hear a prognosis, before delivering it $\left[68^{\circ \bullet}\right]$.

When a patient's condition first becomes incurable, information about how their function may deteriorate can be as important as life expectancy estimates in allowing patients to pursue achievable goals and make practical plans for future decline [70]. This information could also help inform their decisions about treatment, as more aggressive care could reduce their ability to "live well" until they die [71]. Over time, patients' goals and prospects are likely to change and so a step-wise approach of continued conversations about prognosis is needed [72]. When patients reach the end of cancer-directed therapies, clinicians can focus on the care that will continue to be provided rather than describing palliative and supportive care as "doing nothing" [73, 74]. Prognostic discussions are an opportunity to reframe hope by being honest about the difficulties the patient is facing and emphasising symptom control, continuing relationships between clinicians and patients, and establishing achievable goals that optimise quality of life [75]. As the disease progresses, function becomes less relevant and time is more important to allow patients and relatives to make necessary arrangements, say goodbye, and provide the opportunity for relatives to be present when the patient dies [76]. Research has also shown that families often have a greater desire for prognostic information than patients when death is imminent $[77,78]$. It is therefore important to take the patient's lead on how much information to provide and be aware that separate conversations with families may be needed [79]. 
Prognostic uncertainty and lack of confidence discussing this with patients are key reasons for clinicians to avoid prognostic conversations, and so learning how to communicate an uncertain prognosis is important [80]. Current evidence-based guidelines emphasise the importance of stating prognostic uncertainty, but this is not the same as saying, "I do not know" or "it's impossible to judge" $\left[81-83,84^{\circ}\right]$. There is no evidence to suggest whether providing estimates in temporal or probabilistic terms is the better approach when communicating prognosis. However, the use of numerical information in doctor-patient communication has been found to be contentious and the way in which it is received shifts depending on context and stage of illness [85]. In this study, patients felt statistics were used by clinicians with inadequate communication skills to subvert the need to confront difficult emotions or discussions. In practice, clinicians commonly use broad categories (e.g. days to weeks) to discuss prognosis with advanced cancer patients [86]. This approach is a useful way to couch prognostic uncertainty, as it provides patients and families with a meaningful prognosis without giving a spuriously precise estimate [87].

\section{Building skills to improve prognostic discussions}

Recent trials of communication training for oncologists have shown some promising results. Interventions have shown improvement in patient-centred and empathetic communication, earlier and more regular prognostic conversations, and reductions in anxiety, but have struggled to improve prognostic awareness and goal-concordant care $\left[88,89,90^{\circ}, 91\right]$. Examination of real-life conversations may help identify which elements of communication are most able to influence the interaction. The "Real Talk" training programme provides learning points based on analysis of naturally occurring conversations and uses clips to provide real-life examples for trainees [92]. A similar approach has been used in communication training in other settings with promising results [93, 94]. Oncologists and palliative care clinicians have more experience of discussing prognosis than most specialists, and so the approach of basing recommendations on real-life interactions, and building on clinicians' pre-existing skills, could be a useful learning strategy for other less-experienced clinicians. Any guidance or training for oncologists about how to communicate prognosis must also provide them with skills to respond appropriately to expressions of emotion. Derry and colleagues suggest various strategies to address emotional responses such as allowing silence, validating emotions, and signposting to psychological services where necessary $\left[95^{\circ}\right]$. There are also a number of organisational factors that could contribute to better communication of prognosis. These include allowing sufficient time to discuss prognosis, allowing patients to ask questions [96], better integration of oncology with palliative care [97], and support for clinicians through encouragement of reflective practice [98].

\section{Conclusion and recommendations}

The ability to formulate and communicate a prognosis has advantages for the patient, their families, and for clinical teams. Viewing prognostication as a clinical skill invites us to understand that this is something that can be practised and improved. Taking note of one's own prognostic predictions and following them up may help practitioners to practice reflectively and to hone their 
prognostic skills through feedback. When possible, a discussion with a multiprofessional team should be conducted as this may help refine the prognostic estimate. Practitioners should also consider using prognostic tools to support their decision-making, but should remain aware that the prognostic tools themselves are also frequently inaccurate and should currently only be used as an aid towards, rather than a replacement of, clinical decision-making.

Clinicians find talking about prognosis difficult, both in terms of how to initiate these conversations and how to conduct them. Offering opportunities to ask questions or encouraging patients to elaborate on their thoughts allows them to steer the consultation, if they wish, towards prognostic discussions. If patients make statements that hint that they are ready to start having prognostic discussions, these should be explored, not ignored. Uncertainty is a key element that needs to be conveyed during these conversations. On a practical level, this can often be achieved by describing prognosis in terms of general time frames (e.g. "hours", "days", "weeks", "months", or "years") rather than using precise estimates or complex statistical concepts such as probability or risk.

\section{Compliance with Ethical Standards}

\section{Conflict of Interest}

Christina Chu declares that she has no conflict of interest. Rebecca Anderson declares that she has no conflict of interest. Nicola White declares that she has no conflict of interest. Patrick Stone declares that he has no conflict of interest.

\section{Human and Animal Rights and Informed Consent}

This article does not contain any studies with human or animal subjects performed by any of the authors.

\section{Open Access}

This article is licensed under a Creative Commons Attribution 4.0 International License, which permits use, sharing, adaptation, distribution and reproduction in any medium or format, as long as you give appropriate credit to the original author(s) and the source, provide a link to the Creative Commons licence, and indicate if changes were made. The images or other third party material in this article are included in the article's Creative Commons licence, unless indicated otherwise in a credit line to the material. If material is not included in the article's Creative Commons licence and your intended use is not permitted by statutory regulation or exceeds the permitted use, you will need to obtain permission directly from the copyright holder. To view a copy of this licence, visit http://creativecommons.org/licenses/by/4.0/.

\section{References and Recommended Reading}

Papers of particular interest, published recently, have been highlighted as:

- Of importance

$\bullet \quad$ Of major importance

1. Innes S, Payne S. Advanced cancer patients' prognostic 2 information preferences: a review. Palliat Med. 2009;23(1):29-39. https://doi.org/10.1177/ 0269216308098799.

2. Rohde G, Söderhamn U, Vistad I. Reflections on communication of disease prognosis and life expectancy by patients with colorectal cancer undergoing palliative care: a qualitative study. BMJ 
Open. 2019;9:e023463. https://doi.org/10.1136/ bmjopen-2018-023463.

3. Steinhauser KE, Christakis NA, Clipp EC, McNeilly M, McIntyre L, Tulsky JA. Factors considered important at the end of life by patients, family, physicians, and other care providers. JAMA. 2000;284(19):2476-82.

4. LeBlanc TW, Temel JS, Helft PR. "How Much Time Do I Have?": communicating prognosis in the era of exceptional responders. American Society of Clinical Oncology Educational Book. 2018;38:787-94. https:// doi.org/10.1200/EDBK_201211.

5. Hancock K, Clayton JM, Parker SM, Wal der S, Butow PN, Carrick S, et al. Truth-telling in discussing prognosis in advanced life-limiting illnesses: a systematic review. Palliat Med. 2007;21(6):507-17. https://doi. org/10.1177/0269216307080823.

6. Mack JW, Smith TJ. Reasons why physicians do not have discussions about poor prognosis, why it matters, and what can be improved. J Clin Oncol. 2012;30(22):2715-7. https://doi.org/10.1200/JCO. 2012.42.4564.

7. Christakis N. Death foretold: prophecy and prognosis in medical care. 1st ed. University of Chicago Press; 1999.

8. Glare PA, Sinclair CT. Palliative medicine review: prognostication. J Palliat Med. 2008;11(1):84-103. https://doi.org/10.1089/jpm.2008.9992.

9. Croft P, Altman DG, Deeks JJ, Dunn KM, Hay AD, Hemingway $\mathrm{H}$, et al. The science of clinical practice: disease diagnosis or patient prognosis? Evidence about "what is likely to happen" should shape clinical practice. BMC Med. 2015;13:20. https://doi.org/10.1186/ s12916-014-0265-4.

10. Cheon S, Agarwal A, Popovic M, Milakovic M, Lam M, $\mathrm{Fu} \mathrm{W}$, et al. The accuracy of clinicians' predictions of survival in advanced cancer: a review. Annals of Palliative Medicine. 2015;5(1):22-9-9. https://doi.org/10. 3978/j.issn.2224-5820.2015.08.04.

11. • White N, Reid F, Harris A, Harries P, Stone PA. Systematic review of predictions of survival in palliative care: how accurate are clinicians and who are the experts? PLOS ONE. 2016;11(8):e0161407. https://doi. org/10.1371/journal.pone.0161407

Clear summary of current evidence on the accuracy of clinician prognostic predictions.

12. Glare P, Virik K, Jones M, Hudson M, Eychmuller S, Simes J, et al. A systematic review of physicians' survival predictions in terminally ill cancer patients. BMJ. 2003;327(7408):195-8. https://doi.org/10.1136/bmj. 327.7408.195.

13. Maltoni M, Caraceni A, Brunelli C, Broeckaert B, Christakis N, Eychmueller S, et al. Prognostic factors in advanced cancer patients: evidence-based clinical recommendations-a study by the Steering Committee of the European Association for Palliative Care. J Clin Oncol. 2005;23(25):6240-8. https://doi.org/10.1200/ JCO.2005.06.866

14. •• Simmons CPL, McMillan DC, McWilliams K, Sande TA, Fearon KC, Tuck S, et al. Prognostic tools in patients with advanced cancer: a systematic review. Journal of Pain and Symptom Management. 2017;53(5):962-70.e10. https:// doi.org/10.1016/j.jpainsymman.2016.12.330

Useful overview and descriptions of validated prognostic tools available.

15. Lynn J. Living long in fragile health: the new demographics shape end of life care. Hastings Cent Rep. 2005;35(7):s14s8. https://doi.org/10.1353/har.2005.0096.

16. Cohen LM, Ruthazer R, Moss AH, Germain MJ. Predicting six-month mortality for patients who are on maintenance hemodialysis. CJASN. 2010;5(1):72-9. https://doi.org/10.2215/CJN.03860609.

17. Hamano J, Morita $T$, Inoue S, Ikenaga M, Matsumoto $\mathrm{Y}$, Sekine R, et al. Surprise questions for survival prediction in patients with advanced cancer: a multicenter prospective cohort study. Oncologist. 2015;20(7):839-44. https://doi.org/10.1634/ theoncologist.2015-0015.

18. Weijers F, Veldhoven C, Verhagen C, Vissers K, Engels $\mathrm{Y}$. Adding a second surprise question triggers general practitioners to increase the thoroughness of palliative care planning: results of a pilot RCT with case vignettes. BMC Palliat Care. 2018;17(1):64. https://doi.org/10. 1186/s12904-018-0312-6.

19. Royal College of General Practitioners. Matters of life and death: helping people to live well until they die. General practice guidance for implementing the RCGP/RCN end of life care patient charter; 2012.

20. Amano K, Maeda I, Shimoyama S, Shinjo T, Shirayama $\mathrm{H}$, Yamada T, et al. The accuracy of physicians' clinical predictions of survival in patients with advanced cancer. Journal of Pain and Symptom Management. 2015;50(2):139-46.e1. https://doi.org/10.1016/j. jpainsymman.2015.03.004.

21. Urahama N, Sono J, Yoshinaga K. Comparison of the accuracy and characteristics of the prognostic prediction of survival of identical terminally ill cancer patients by oncologists and palliative care physicians. Jpn J Clin Oncol. 2018;48(7):695-8. https://doi.org/10. 1093/jjco/hyy080.

22. Razvi Y, Chan S, Zhang L, Tsao M, Barnes E, Danjoux C, et al. Are we better a decade later in the accuracy of survival prediction by palliative radiation oncologists? Annals of Palliative Medicine. 2018;8(2):150-88. https://doi.org/10.21037/apm.2018.11.02.

23. Gramling R, Gajary-Coots E, Cimino J, Fiscella K, Epstein R, Ladwig S, et al. Palliative care clinician overestimation of survival in advanced cancer: disparities and association with end-of-life care. J Pain Symptom Manag. 2019;57(2):233-40. https://doi.org/10.1016/ j.jpainsymman.2018.10.510.

24. Ermacora P, Mazzer M, Isola M, Pascoletti G, Gregoraci G, Basile D, et al. Prognostic evaluation in palliative care: final results from a prospective cohort study. Support Care Cancer. 2019;27(6):2095-102. https:// doi.org/10.1007/s00520-018-4463-z.

25. Vasista A, Stockler M, Martin A, Pavlakis N, Sjoquist K, Goldstein D et al. Accuracy and prognostic significance of oncologists' estimates and scenarios for survival 
time in advanced gastric cancer. Oncologist. 2019. doi: https://doi.org/10.1634/theoncologist.2018-0613. [Epub ahead of print].

26. Simmons C, McMillan DC, Tuck S, Graham C, McKeown A, Bennett M, et al. How Long Have I Got?-a prospective cohort study comparing validated prognostic factors for use in patients with advanced cancer. Oncologist. 2019. https://doi.org/10.1634/ theoncologist.2018-0474.

27. Farinholt P, Park M, Guo Y, Bruera E, Hui D. A comparison of the accuracy of clinician prediction of survival versus the palliative prognostic index. J Pain Symptom Manag. 2018;55(3):792-7. https://doi.org/ 10.1016/j.jpainsymman.2017.11.028.

28. Tavares T, Oliveira M, Gonçalves J, Trocado V, Perpétuo J, Azevedo A, et al. Predicting prognosis in patients with advanced cancer: a prospective study. Palliat Med. 2018;32(2):413-6. https://doi.org/10.1177/ 0269216317705788 .

29. Malhotra K, Fenton JJ, Duberstein PR, Epstein RM, Xing G, Tancredi DJ, et al. Prognostic accuracy of patients, caregivers, and oncologists in advanced cancer. Cancer. 2019. https://doi.org/10.1002/cncr.32127.

30. Perez-Cruz PE, dos Santos R, Silva TB, Crovador CS, Nascimento MSA, Hall S, et al. Longitudinal temporal and probabilistic prediction of survival in a cohort of patients with advanced cancer. J Pain Symptom Manag. 2014;48(5):875-82. https://doi.org/10.1016/j. jpainsymman.2014.02.007.

31. Brier GW. Verification of forecasts expressed in terms of probability. Mon Weather Rev. 1950;78:1. https://doi. org/10.1175/1520-0493(1950)078<0001:VOFEIT $>2$. $0 . \mathrm{CO} ; 2$.

32. Kee F, Owen $\mathrm{T}$, Leathem R. Offering a prognosis in lung cancer: when is a team of experts an expert team? J Epidemiol Community Health. 2007;61(4):308-13. https://doi.org/10.1136/jech.2005.044917.

33. White N, Harries P, Harris AJL, Vickerstaff V, Lodge P, McGowan C, et al. How do palliative care doctors recognise imminently dying patients? A judgement analysis. BMJ Open. 2018;8(11):e024996. https://doi.org/10. 1136/bmjopen-2018-024996

The first study to use this method to probe clinicians' subconscious decision-making in recognising patients who are in the final days of life.

34. Gwilliam B, Keeley V, Todd C, Gittins M, Roberts C, Kelly $\mathrm{L}$, et al. Development of prognosis in palliative care study (PiPS) predictor models to improve prognostication in advanced cancer: prospective cohort study. BMJ. 2011;343:d4920. https://doi.org/10.1136/ bmj.d4920.

35. Gwilliam B, Keeley V, Todd C, Roberts C, Gittins M, Kelly L, et al. Prognosticating in patients with advanced cancer-observational study comparing the accuracy of clinicians' and patients' estimates of survival. Ann Oncol. 2013;24(2):482-8. https://doi.org/10.1093/ annonc/mds 341 .

36. Ericsson KA, Krampe RT, Tesch-Römer C. The role of deliberate practice in the acquisition of expert performance. Psychol Rev. 1993;100:363-406. https:// doi.org/10.1037//0033-295X.100.3.363.

37. Ericsson K. Acquisition and maintenance of medical expertise: a perspective from the expert-performance approach with deliberate practice. Acad Med. 2015;90(11):1471-86. https://doi.org/10.1097/ACM. 0000000000000939.

38. White N, Kupeli N, Vickerstaff V, Stone P. How accurate is the 'Surprise Question' at identifying patients at the end of life? A systematic review and meta-analysis. BMC Med. 2017;15(1):139. https://doi.org/10.1186/ s12916-017-0907-4.

39. Downar J, Goldman R, Pinto R, Englesakis M, Adhikari NKJ. The "surprise question" for predicting death in seriously ill patients: a systematic review and metaanalysis. CMAJ. 2017;189(13):E484-E93. https://doi. org/10.1503/cmaj.160775.

40. Fromme EK, Smith MD, Bascom PB, KenworthyHeinige T, Lyons KS, Tolle SW. Incorporating routine survival prediction in a U.S. hospital-based palliative care service. J Palliat Med. 2010;13(12):1439-44. https://doi.org/10.1089/jpm.2010.0152.

41. Zibelman M, Xiang Q, Muchka S, Nickoloff S, Marks S. Assessing prognostic documentation and accuracy among palliative care clinicians. J Palliat Med. 2014;17(5):521-6. https://doi.org/10.1089/jpm. 2013.0454.

42. Gripp S, Moeller S, Bölke E, Schmitt G, Matuschek C, Asgari S, et al. Survival prediction in terminally ill cancer patients by clinical estimates, laboratory tests, and self-rated anxiety and depression. J Clin Oncol. 2007;25(22):3313-20. https://doi.org/10.1200/JCO. 2006.10 .5411 .

43. Mackillop WJ, Quirt CF. Measuring the accuracy of prognostic judgments in oncology. J Clin Epidemiol. 1997;50(1):21-9. https://doi.org/10.1016/s08954356(96)00316-2.

44. Oxenham D, Cornbleet MA. Accuracy of prediction of survival by different professional groups in a hospice. Palliat Med. 1998;12:117-8. https://doi.org/10.1191/ 026921698672034203.

45. Domeisen Benedetti F, Ostgathe C, Clark J, Costantini M, Daud ML, Grossenbacher-Gschwend B, et al. International palliative care experts' view on phenomena indicating the last hours and days of life. Support Care Cancer. 2013;21(6):1509-17. https://doi.org/10. 1007/s00520-012-1677-3.

46. Taylor P, Dowding D, Johnson M. Clinical decision making in the recognition of dying: a qualitative interview study. BMC Palliat Care. 2017;16(1):11. https://doi.org/10.1186/s12904-016-0179-3.

47. Stewart T. Judgment analysis: procedures advances in psychology 1988;54:41-74. doi:https://doi.org/10. 1016/S0166-4115(08)62170-6.

48. White N, Oostendorp LJM, Tomlinson C, Yardley S, Ricciardi F, Gökalp H, Minton O, Boland JW, Clark B, Harries P and Stone P. Online training improves medical students' ability to recognise when a person is 
dying: the ORaClES randomised controlled trial. Palliat Med in press.

49. Eychmüller S, Benedetti FD, Latten R, Tal K, Walker J, Costantini M. 'Diagnosing dying' in cancer patients - a systematic literature review. Eur J Palliat Care. 2013;20(6):292-6.

50. Bruera S, Chisholm G, Dos Santos R, Crovador C, Bruera E, Hui D. Variations in vital signs in the last days of life in patients with advanced cancer. J Pain Symptom Manag. 2014;48(4):510-7. https://doi.org/10. 1016/j.jpainsymman.2013.10.019.

51. Hui D, dos Santos R, Chisholm G, Bansal S, Silva TB, Kilgore $\mathrm{K}$, et al. Clinical signs of impending death in cancer patients. Oncologist. 2014;19(6):681-7. https://doi.org/10.1634/theoncologist.2013-0457.

52. Hui D, Dos Santos R, Chisholm G, Bansal S, Souza Crovador C, Bruera E. Bedside clinical signs associated with impending death in patients with advanced cancer: preliminary findings of a prospective, longitudinal cohort study. Cancer. 2015;121(6):960-7. https://doi. org/10.1002/cncr.29048.

53. Hui D, Hess K, Santos R, Chisholm G, Bruera E. A diagnostic model for impending death in cancer patients: preliminary report. Cancer.

2015;121(21):3914-21. https://doi.org/10.1002/cncr. 29602.

54. Karnofsky D, Burchenal J. The clinical evaluation of chemotherapeutic agents in cancer. In: MacLeod C, editor. Evaluation of chemotherapeutic agents. New York: Columbia University Press. p. 191-205.

55. Abernethy AP, Shelby-James T, Fazekas BS, Woods D, Currow DC. The Australia-modified Karnofsky Performance Status (AKPS) scale: a revised scale for contemporary palliative care clinical practice. BMC Palliat Care. 2005;4(1):7. https://doi.org/10.1186/1472684X-4-7.

56. Anderson F, Downing GM, Hill J, Casorso L, Lerch N. Palliative performance scale (PPS): a new tool. J Palliat Care. 1996;12(1):5-11.

57. Oken MM, Creech RH, Tormey DC, Horton J, Davis TE, McFadden ET, et al. Toxicity and response criteria of the Eastern Cooperative Oncology Group. Am J Clin Oncol. 1982;5:649-55. https://doi.org/10.1097/ 00000421-198212000-00014.

58. Downing M, Lau F, Lesperance M, Karlson N, Shaw J, Kuziemsky C, et al. Meta-analysis of survival prediction with Palliative Performance Scale. J Palliat Care 2007;23:245-252; discussion 252-254. doi:https:// doi.org/10.1177/082585970702300402.

59. Suh S-Y, LeBlanc TW, Shelby RA, Samsa GP, Abernethy AP. Longitudinal patient-reported performance status assessment in the cancer clinic is feasible and prognostic. JOP. 2011;7:374-81. https://doi.org/10.1200/ JOP.2011.000434.

60. Albain KS, Crowley JJ, LeBlanc M, Livingston RB. Survival determinants in extensive-stage non-small-cell lung cancer: the Southwest Oncology Group experience. J Clin Oncol. 1991;9:1618-26. https://doi.org/ 10.1200/JCO.1991.9.9.1618.
61. Pirovano $M$, Maltoni $M$, Nanni O, Marinari $M$, Indelli $M$, Zaninetta $G$, et al. A new palliative prognostic score: a first step for the staging of terminally ill cancer patients. Italian Multicenter and Study Group on Palliative Care. J Pain Symptom Manag. 1999;17(4):231-9. https://doi.org/10. 1016/s0885-3924(98)00145-6.

62. Scarpi E, Maltoni M, Miceli R, Mariani L, Caraceni A, Amadori D, et al. Survival prediction for terminally ill cancer patients: revision of the palliative prognostic score with incorporation of delirium. Oncologist. 2011;16(12):1793-9. https://doi.org/10.1634/ theoncologist.2011-0130.

63. Morita T, Tsunoda J, Inoue S, Chihara S. The palliative prognostic index: a scoring system for survival prediction of terminally ill cancer patients. Support Care Cancer. 1999;7(3):128-33.

64. Forrest LM, McMillan DC, McArdle CS, Angerson WJ, Dunlop DJ. Evaluation of cumulative prognostic scores based on the systemic inflammatory response in patients with inoperable non-small-cell lung cancer. Br J Cancer. 2003;89(6):1028-30. https://doi.org/10. 1038/sj.bjc.6601242.

65. Geissbühler P, Mermillod B, Rapin CH. Elevated serum vitamin B12 levels associated with CRP as a predictive factor of mortality in palliative care cancer patients: a prospective study over five years. J Pain Symptom Manag. 2000;20(2):93-103. https://doi.org/10.1016/ s0885-3924(00)00169-x.

66. Singh S, Cortez D, Maynard D, Cleary JF, DuBenske L, Campbell TC. Characterizing the nature of scan results discussions: insights into why patients misunderstand their prognosis. J Oncol Pract. 2017;13(3):e231-e9. https://doi.org/10.1200/JOP.2016.014621.

67. The AM, Hak T, Koëter G, van der Wal G. Collusion in doctor-patient communication about imminent death: an ethnographic study. West J Med. 2001;174(4):24753. https://doi.org/10.1136/ewjm.174.4.247.

68. $\bullet$ Pino M, Parry R. How and when do patients request life-expectancy estimates? Evidence from hospice medical consultations and insights for practice. Patient Educ Couns. 2019;102(2):223-37. https://doi.org/10. 1016/j.pec.2018.03.026

Demonstrates how doctors successfully identify and navigate patient prompts to talk about prognosis.

69. Pino M, Parry R, Land V, Faull C, Feathers L, Seymour J. Engaging terminally ill patients in end of life talk: how experienced palliative medicine doctors navigate the dilemma of promoting discussions about dying. PLoS One. 2016;11(5):e0156174. https://doi.org/10.1371/ journal.pone.0156174.

70. Paladino J, Lakin JR, Sanders JJ. Communication strategies for sharing prognostic information with patients: beyond survival statistics. JAMA. 2019. https://doi.org/ 10.1001/jama.2019.11533.

71. Wright AA, Zhang B, Ray A, Mack JW, Trice E, Balboni $\mathrm{T}$, et al. Associations between end-of-life discussions, patient mental health, medical care near death, and caregiver bereavement adjustment. JAMA. 
2008;300(14):1665-73. https://doi.org/10.1001/ jama.300.14.1665.

72. Jackson VA, Jacobsen J, Greer JA, Pirl WF, Temel JS, Back AL. The cultivation of prognostic awareness through the provision of early palliative care in the ambulatory setting: a communication guide. J Palliat Med. 2013;16(8):894-900. https://doi.org/10.1089/ jpm.2012.0547.

73. Zimmermann C, Swami N, Krzyzanowska M, Leighl N, Rydall A, Rodin G, et al. Perceptions of palliative care among patients with advanced cancer and their caregivers. CMAJ. 2016;188(10):E217-E27. https://doi. org/10.1503/cmaj.151171.

74. Koedoot CG, Oort FJ, de Haan RJ, Bakker PJM, de Graeff A, de Haes JCJM. The content and amount of information given by medical oncologists when telling patients with advanced cancer what their treatment options are: palliative chemotherapy and watchfulwaiting. Eur J Cancer. 2004;40(2):225-35. https://doi. org/10.1016/j.ejca.2003.10.008.

75. Clayton JM, Hancock K, Parker S, Butow PN, Walder S, Carrick S, et al. Sustaining hope when communicating with terminally ill patients and their families: a systematic review. Psychooncology. 2008;17(7):641-59. https://doi.org/10.1002/pon.1288.

76. Witkamp FE, van Zuylen L, Vergouwe Y, Rijt, CCD, van der Heide A. Concordance between experiences of bereaved relatives, physicians, and nurses with hospital end-of-life care: everyone has their "Own Truth". International Journal of Palliative Care. 2015 (Article ID 623890).

77. Parker SM, Clayton JM, Hancock K, Walder S, Butow PN, Carrick S, et al. A systematic review of prognostic/ end-of-life communication with adults in the advanced stages of a life-limiting illness: patient/caregiver preferences for the content, style, and timing of information. J Pain Symptom Manag. 2007;34(1):81-93. https://doi.org/10.1016/j.jpainsymman.2006.09.035.

78. Kirk P, Kirk I, Kristjanson LJ. What do patients receiving palliative care for cancer and their families want to be told? A Canadian and Australian qualitative study. BMJ. 2004;328(7452):1343. https://doi.org/10.1136/ bmj.38103.423576.55.

79. Washington KT, Craig KW, Parker Oliver D, Ruggeri JS, Brunk SR, Goldstein AK, et al. Family caregivers' perspectives on communication with cancer care providers. J Psychosoc Oncol. 2019:1-14. https://doi.org/ 10.1080/07347332.2019.1624674.

80. Travers A, Taylor V. What are the barriers to initiating end-of-life conversations with patients in the last year of life? Int J Palliat Nurs. 2016;22(9):454-62. https:// doi.org/10.12968/ijpn.2016.22.9.454.

81. Bernacki RE, Block SD, American College of Physicians High Value Care Task F. Communication about serious illness care goals: a review and synthesis of best practices. JAMA Intern Med. 2014;174(12):1994-2003. https://doi.org/10.1001/jamainternmed.2014.5271.

82. Clayton JM, Hancock KM, Butow PN, Tattersall MHN, Currow DC, Australian and New Zealand Expert
Advisory Group, et al. Clinical practice guidelines for communicating prognosis and end-of-life issues with adults in the advanced stages of a life-limiting illness, and their caregivers. Med J Aust. 2007;186(12 Suppl):S77,-S9-83-108.

83. National Institute of Health and Care Excellence. Care of dying adults in the last days of life [NG31]. NICE; 2015.

84. •• Royal College of Physicians. Talking about dying: how to begin honest conversations about what lies ahead: Royal College of Physicians; 2018.

Evidence-based report providing clinicians clear information about barriers, common myths, recommendations, and further resources to help discussions with patients about their end-oflife care.

85. Thorne S, Hislop TG, Kuo M, Armstrong E-A. Hope and probability: patient perspectives of the meaning of numerical information in cancer communication. Qual Health Res. 2006;16(3):318-36. https://doi.org/ $10.1177 / 1049732305285341$.

86. Henselmans I, Smets EMA, Han PKJ, de Haes HCJC, Laarhoven HWM. How long do I have? Observational study on communication about life expectancy with advanced cancer patients. Patient Educ Couns. 2017;100(10):1820-7. https://doi.org/10.1016/j.pec. 2017.05.012.

87. Anderson R, Stone P, Low J, Bloch S. P01-098 Discussing prognosis and managing uncertainty in end-of-life conversations with family members: a conversation analytic study. European Association for Palliative Care; 2019. Berlin, Germany: Palliative Medicine.

88. Bernacki R, Paladino J, Neville BA, Hutchings M, Kavanagh J, Geerse OP, et al. Effect of the serious illness care program in outpatient oncology: a cluster randomized clinical trial. JAMA Intern Med. 2019;179(6):751-9. https://doi.org/10.1001/ jamainternmed.2019.0077.

89. Epstein RM, Duberstein PR, Fenton JJ, Fiscella K, Hoerger M, Tancredi DJ, et al. Effect of a patientcentered communication intervention on oncologistpatient communication, quality of life, and health care utilization in advanced cancer: the VOICE randomized clinical trial. JAMA Oncol. 2017;3(1):92-100. https:// doi.org/10.1001/jamaoncol.2016.4373.

90. • Paladino J, Bernacki R, Neville BA, Kavanagh J, Miranda SP, Palmor M et al. Evaluating an intervention to improve communication between oncology clinicians and patients with life-limiting cancer: a cluster randomized clinical trial of the serious illness care program. JAMA Oncol 2019;5(6):801-809. doi:https://doi.org/10. 1001/jamaoncol.2019.0292.

Demonstrates the benefits of introducing a communication intervention across a whole institution using a robust study design.

91. Moore PM, Rivera S, Bravo-Soto GA, Olivares C, Lawrie TA. Communication skills training for healthcare professionals working with people who have cancer. Cochrane Database Syst Rev. 2018;7:CD003751. https://doi.org/10.1002/14651858.CD003751.pub4. 
92. Real Talk. Video-based communication training. [Internet] [updated 2019; cited 2019 Sept 23] Available from: https://www.realtalktraining.co.uk/

93. O'Brien R, Goldberg SE, Pilnick A, Beeke S, Schneider J, Sartain K, et al. The VOICE study - a before and after study of a dementia communication skills training course. PLoS One. 2018;13(6):e0198567. https://doi. org/10.1371/journal.pone.0198567.

94. Jenkins L, Reuber M. A conversation analytic intervention to help neurologists identify diagnostically relevant linguistic features in seizure patients' talk. Res Lang Soc Interact. 2014;47(3):266-79. https://doi.org/ 10.1080/08351813.2014.925664.

95. - Derry HM, Epstein AS, Lichtenthal WG, Prigerson HG. Emotions in the room: common emotional reactions to discussions of poor prognosis and tools to address them. Expert Rev Anticancer Ther. 2019;19(8):689-96. https://doi.org/10.1080/14737140.2019.1651648

Expert opinion on how to manage a range of emotional reactions during conversations about prognosis.

96. Piggott KL, Patel A, Wong A, Martin L, Patel A, Patel M, et al. Breaking silence: a survey of barriers to goals of care discussions from the perspective of oncology practitioners. BMC Cancer. 2019;19(1):130. https:// doi.org/10.1186/s12885-019-5333-X.

97. Kaasa S, Loge JH, Aapro M, Albreht T, Anderson R, Bruera E, et al. Integration of oncology and palliative care: a Lancet Oncology Commission. Lancet Oncol. 2018;19(11):e588-653. https://doi.org/10.1016/ S1470-2045(18)30415-7.

98. Brighton LJ, Selman LE, Bristowe K, Edwards B, Koffman J, Evans CJ. Emotional labour in palliative and end-of-life care communication: a qualitative study with generalist palliative care providers. Patient Educ Couns. 2019;102(3):494-502. https://doi.org/ 10.1016/j.pec.2018.10.013.

\section{Publisher's note}

Springer Nature remains neutral with regard to jurisdictional claims in published maps and institutional affiliations. 